\title{
A INFLUENCIA DA OBRA DE WANDA DE AGUIAR HORTA NA ENFERMAGEM BRASILEIRA
}

Lygia Paim M. Dias`

DIAS, L. P. M. A influência da obra de Wanda de Aguiar Horta na enfermagem brasileira. Rev. Esc. Enf. USP, São Paulo, 22 (n. especial): 14-20, jun. 1988.

A autora comenta a vida e obra de Dra. Wanda de Aguiar Horta, bem como rememora os principais aspectos da influência da obra desta no desenvolvimento da enfermagem brasileira, orientada pelo trabalho de Júnia Villela Gonçalves.

UNITERMOS: Wanda de Aguiar Horta. Enfermagem - Brasil.

Atendo com elevada honra a este convite para comentar a vida e obra de Dra. Wanda de Aguiar Horta, desta feita orientada pelo trabalho de uma colega, Júnia Villela Gonçalves, concorrente este ano de 1987 ao prêmio Grandes Educadores Brasileiros, promovido pelo INEP/MEC. É ao comentar o referido trabalho que me flagro recorrendo à memória e, por circunstâncias, assim reconstituindo outros fragmentos biográficos que, por si sós, garantem um repasse dos principais aspectos da influência da obra de Wanda Horta na enfermagem brasileira.

Creio que pecarei metodologicamente quanto à contribuição que quero dar ao trabalho, sobretudo no que tange à decisão de excluir o que é redundante e não omitir nada que é significativo, ao lado da regra técnica de que não é preciso entrar em detalhes. Valho-me portanto, do privilégio de poder apresentar Wanda Horta, sua obra e a influência da mesma, tal como eu as vejo.

- Silhueta do contato vital com Wanda Horta

Uma lembrança ainda recente reporta a Escola Ana Néri em seu Ensino de Mestrado, a uma época de amável convívio escolar, quando conhecemos Wanda Horta, mais de perto e aprendemos a admirá-la profundamente.

Voltamos a falar de ti, Wanda Horta, neste encontro de hoje, tal como o fazíamos em salas de aula, durante o tempo em que eras professora do Curso de Mestrado em Enfermagem da Escola Ana Néri. Chegavas ao Rio para as aulas semanais e, carregada de papéis, plena de novas idéias,

- Professora Titular da Escola de Enfermagem Ana Néri - UFRJ. Docente-Llvre/UFRJ Mestra em Enfermagem Fundamental - Tese de Mestrado orlentada por Dra. Wanda Horta em 1975. 
mansamente, tomavas conta de tudo, do afeto do grupo, do desânimo de alguns, do sucesso de outros, e da curiosidade de todos, ante ao que teríamos de novo a aprender após as últimas lições deixadas por ti quando da vez em que estiveste na aula anterior.

Durante a tua fala, o olhar de expectação, mãos crispadas a arranjar teus cabelos grisalhos, bitonavas aqui e ali a voz suave, talvez já cansada das lutas empreendidas. Já àquela época aprendíamos a avaliar o quão difícil seria enfrentar resistências.

"Gente que cuida de gente" - este era o lema a desenhar gestalticamente a questão mais vital para ti, Wanda, o mesmo que nos estimulava a criar matrizes que se multiplicassem infinitamente até o alcance do modelo pretendido. Como batalhadora, lidaste com oposições silenciosas mas consideraste tudo controvérsia a teu trabalho, nada além de incompreensão própria de fases primeiras...

Incansavelmente lutaste até o fim. Mas foram bonitas as veredas floridas que algumas vezes pudeste percorrer.

Tua obra está sobrevivendo caracterizada que foi pela grandeza de teus ensinamentos e das tuas preocupações em perceber o sentimento do outro.

Nivelar os direitos e valorizar o amor e o respeito entre os homens era tua constante porque só assim entendias a trajetória para a construção de uma humanidade melhor.

A Teoria das Necessidades Humanas Básicas que tanto de teus estudos e observações mereceu, é parte da tua obra e apoiou-se, como era de se esperar, em fenômenos autênticos e universais que revelaram o valor da interioridade humana, a assegurar equilíbrio e adaptação eficientes ao ajustamento do homem a outro homem. Tua preocupação era tratar a natureza peculiar do ser humano. Era o respeito e dignidade que imprimias à autoridade inominável do homem.

Ao revisar a tua concepção teórica, revisamos o teu gesto maior de correr com a vida para te ultrapassares profissionalmente. Criar, em ti, tornou-se mais importante que continuar vivendo. Estavas lúcida quando te sabias predestinada a compor a obra que compuseste, mesmo quando teus movimentos para consubstanciá-la tivesse, como todo caminho de transformação, dividido opiniões, causado outros movimentos, se mostrado por vezes, como que permeados de adversidades e incompreensões. No entanto, nesse complexo de circunstâncias, nunca estiveste só apesar do caminho solitário de trabalhar o que nos deixaria em futuro.

E por tudo isto que ao te conhecer muitas vezes te confundimos com a tua obra, porque pelas tuas idéias pode-se compreender a tua grandeza $e$ a influência que tens na profissão que viveste.

É assim que recordo as tuas palavras firmes e suaves ao dizer a muitos de nós, teus alunos, sobre tua teoria: "sempre restará esperar que 
outros novos estudos, pesquisas e investigações a confirmem ou a refutem". Na tua fala, a definição de teoria carregada de flexibilidade, de dinâmica, de característica retificável. $\mathrm{Na}$ tua expressão, a esperança colocada em teus alunos quando os responsabilizava por estudar e buscar respostas para as perguntas que te faziam e tu já não ias ter tempo para responder aqui na terra.

"As diversas correntes metodológicas, a consciência crítica cada vez mais aguçada dos enfermeiros estudiosos de amanhã, buscarão compreender as versões mais diversas do que serão as transformações mais necessárias do mundo e do tempo em que viverem", dizias tu, quando mostravas que é importante a atitude da abertura oferecendo guarida e acolhimento aos que investem energias em pesquisa. Aconselhavas à época, de modo revolucionário, que era preciso romper com as barreiras impostas à pesquisa. Eras coerente com o teu discurso; tantos limites impostos a ti e tantos rompimentos deliberados teus, para hoje repensarmos o teu pioneirismo na teoria que começaste a escrever no sonho e na convicção de vê-la continuada por outros, os que viriam logo depois de ti, neste mundo, com semelhante postura de reconstrução. Mestra, se tua vida tivesse sido poupada, temos a enorme certeza de que outros estudos e pesquisas teriam proporcionado elementos ainda mais completos ou elaborados para a conclusão da tua teoria inacabada, como sempre querias que fosse vista a tua teoria. Mestra, muito gostaríamos de tomar o teu verbo e dele fazer a nossa melodia constante. Cantá-la aqui e agora seria o mesmo que viver por ti o empenho que reservavas para a concretização dos parâmetros científicos que apoiariam a pesquisa e sustentariam novas teorias de enfermagem. Imaginamos ainda, o quanto te alegrarias, Mestra, ver desenvolvidas as metodologias de tratamento do Processo de Enfermagem, cuidada por ti como se fora um instrumento mágico que, com maestria, soubeste manejar legando-o à utilização de todos os enfermeiros na atenção diária ao paciente internado.

Desejo encerrar esta primeira parte, não sem antes te dizer do orgulho de falar à ti Mestra, em particular porque ensinaste-me a trilhar os passos que tua sábia orientação me ajudou para a obtenção desse grau. Quero dizer-te das reverências dos enfermeiros brasileiros a ti e da influência de tua obra sentida no destaque que vem sendo dado em utilização e citação, quiçá a mais referida entre as obras de construção teórica de enfermeiros brasileiros nos últimos tempos ,a mais conhecida no meio acadêmico de enfermagem no País, a mais tentada por ensaios de uso de conceitos teóricos específicos da profissão no cotidiano de enfermeiros. Mesmo quem ainda não domina a tua obra em conteúdo e significado teórico, ainda assim, não a ignora e tende a indicá-la como uma demarcação de que a partir dela passou a existir um novo tempo de desenvolver um modo heurístico de pensar a enfermagem brasileira.

\section{- O pensamento de enfermagem na obra de Wanda Horta}

O pensamento vivo de uma construção teórica sempre influencia, no mínimo inspirando respeito a esse tipo de trabalho e a enfermagem em 
seus novos rumos tem sabido acolher os méritos dos pouquíssimos autores brasileiros de teorias de enfermagem.

A influência de uma obra não depende do uso que dela se faz num breve tempo; ela se dará no processo. Mesmo porque o valor de uma obra não se prende somente à época em que ela foi escrita. Muitas produções científicas e literárias dentro e fora da Enfermagem aguardam a sua hora.

A obra de Wanda Horta permite ser interpretada, na enfermagem brasileira, como um divisor de épocas - antes de se falar em teorias de enfermagem e depois, quando se fala sobre teorias de enfermagem construída por enfermeiros.

A produção científica de Wanda Horta excede a sua própria teoria, e com essa produção científica ela encorajou os enfermeiros abrindo frente na programação de uma das mais características reuniões da comunidade científica brasileira - a da SBPC. Sua obra então comunicada nessa reunião foi mais um passo para a habitação da enfermagem no espaço da ciência.

Quando na década de setenta a autora Wanda Horta estava construindo sua teoria de enfermagem, evidenciava-se que antes do produto estão as atitudes do cientista como fundamentos desse tipo de construção. A permanente atitude de inquirição de Wanda Horta esteve presa à de colaboração com outros como algo essencial. Manifestava, como autora, forte disposição em recusar a crença isolada de somente aceitar aquilo cuja base estivesse firmada na tradição o que se pode ver até mesmo na denúncia freqüentemente feita quanto ao aprisionamento do cliente às normas e rotinas sem consideração à sua necessidade e direito de compartilhar das decisões que o envolviam.

Não houve hesitação da autora Wanda Horta ao apresentar no seu estudo a necessidade de reconhecer não somente a ciência mas também a arte de enfermagem. Numerosos líderes de enfermagem, desde Florence Nightingale, têm descrito suas preocupações com o subjetivo, orientados humanísticamente, centrado sem valores e, ainda assim organizados objetiva e cientificamente. Também Wanda Horta esteve preocupada com o valor estético e o científico de modo desafiante ainda que assim se mostrem muitos fenômenos em nosso mundo.

A avidez da autora em aprender se confundia com sua sede de ensinar; a ânsia de obter respostas declarava o seu profundo envolvimento com a curiosidade científica mantida na abertura a possíveis novas informações e idéias que mobilizavam os seus alunos no uso da criatividade ao pensar em possíveis novas abordagens para velhos problemas. Muito importante para a autora era o sustento da fé na transformação do mundo ao rítmo, por vezes, ofegante do seu próprio respirar.

Hoje podemos até imaginar que a autora Wanda Horta, como Fernando Pessoa, pensava que a ciência trata as coisas como são, e a arte, como são sentidas, como se sente que são. E ela ousou em sua obra vencer 0 desafio de explicar a realidade da enfermagem na simultaneidade de ciência e arte. 
Uma preocupação levada em conta para o estudo de sua teoria foi o risco que, entendia a autora, a profissão de enfermagem corria ao ser confundida com a medicina ou com a administração como coordenadora da assistência prestada por outros profissionais de saúde. Pensando assim, ela buscou desvendar algumas das cobertas desse nosso caminho profissional ao longo do seu fugaz tempo para fazer tanto. Ela buscou comprovar a enfermagem como uma ciência aplicada e mostrou certo temor quanto a transição entre currentes que dividiam os profissionais de nossa época em futuros assistentes-médicos e estudiosos de uma ciência própria do cuidar.

Foram trinta anos de observações e estudos com reflexões vivenciais que permitiram à autora uma proposta teórica de campo específico desta profissão e a projeção de uma metodologia científica como guia ao desenvolvimento do processo de assistir.

A culminância de sua obra se dá na teoria das necessidades humanas básicas. Trata-se de uma teoria derivada de outra teoria - a da motivação humana, de Maslow. Sua construção partiu de leis gerais que regem os fenômenos universais: a lei do equilíbrio (homeodinâmica), a da adaptação do homem como ser no universo, e a do holismo, o todo não é mera soma das partes constituintes de cada ser.

Duas questões fundamentais foram perseguidas no trabalho de Wanda Horta. A primeira, a quem serve a enfermagem? Respondida finalmente em sua teoria como uma afirmação: "a enfermagem é um serviço prestado ao ser humano", e a segunda, com que se ocupa a enfermagem? Respondida então que "a enfermagem é parte integrante da equipe de saúde e como tal se ocupa em manter o equilíbrio dinâmico, prevenir desequilíbrios e reverter desequilíbrios em equilíbrio do ser humano".

Como fenômenos centrais, Wanda Horta desenvolveu em seus estudos os conceitos de ENFERMAGEM, ASSISTIR EM ENFERMAGEM e PROCESSO DE ENFERMAGEM.

No seu conceito de Enfermagem estão presentes: a dualidade ciência e arte; o ser humano na ótica de suas necessidades básicas; o auto-cuidado como uma possibiildade; e, finalmente, a colaboração da enfermagem com os demais profissionais no objetivo comum de encontrar a SAÚDE.

No seu conceito de Assistir em Enfermagem a presença da AJUDA surge como o elemento constante. Assistir em Enfermagem consiste em: fazer por, ajudar a, orientar em, supervisionar, encaminhar a, como afazeres próprios da enfermagem. É neste aspecto do estudo que as funções do enfermeiro ficam visualisadas em três campos: o específico, o de interdependência ou de colaboração, e o social.

Um outro conceito o de Processo de Enfermagem foi visto pela teoria na qualidade de abordagem metodológica do trabalho do enfermeiro, fundamentada no método científico e representado na dinâmica de suas ações por uma figura hexagonal.

No bojo do campo específico ou do cuidar consagra-se na teoria o conceito da transição de dependência para a independência do cliente ba- 
seado na referência de que a enfermagem vai além do estágio de fazer pelo outro o que ele próprio não pode fazer, ficando clara a dinâmica, a flexibilidade e a evolução do cuidar e do assistir em enfermagem.

A diferença entre assistir e cuicar mostra-se na teoria de Wanda Hortä quando esta autora consegue comunicar que o cuidado é a unidade terminal resultante da ação planejada, deliberada do enfermeiro, decorrente de sua percepção, observação e análise da situação do ser humano. Enquanto a assistência, em sua teoria é o conjunto de ações organizadas, sistematizadas em processo de enfermagem para desenvolver os cuidados relativos ao atendimento das necessidades básicas do ser humano.

Por sua vez, é no Prognóstico de Enfermagem que surge a intimidade desta teoria com um conceito de autocuidado. É possível interpretar em sua teoria que prognosticar em enfermagem corresponde à estimativa da capacidade do ser humano em conhecer-se no que respeita as suas próprias potencialidades de cuidar-se considerados os recursos disponíveis de atendimento a suas necessidades básicas. A relação entre o prognóstico e o plano assistencial mostra-se na teoria mas não tem parecido suficientemente clara. Quem sabe, não houve tempo para que fosse aprofundada tal explicação.

A influência maior ou menor de uma obra, como de resto tudo na vida, não se dâ por acaso. A história sempre contou o que seremos, e a obra de Wanda Horta é parte da história.

A toerista brasileira Wanda Horta foi plural como o cosmo. Escreveu sobre vida, saúde e enfermagem quando atravessava uma crise de desassossego determinada pela diminuição de suas possibilidades de equilíbrio em saúde. A teorista tinha pressa de chegar a algum lugar e mostrar o seu trabalho. Ela fez muitos achados aqui, antes de nós. Tem portanto Wanda Horta a influência dos mutantes.

Dra. Wanda de Aguiar Horta saiu do cenário terrestre em 1981 e nos legou a sua obra. Nunca a perderemos de vista porque ela era, para nós, do tamanho que ela viu a nossa profissão de Enfermagem.

Relendo seus poemas revemos o seu semblante. Em gratidão, ofereço à Wanda Horta, o meu pensamento poemado de modo livre, espontâneo sentimento, na intenção de lhe mandar uma breve notícia de como vejo o nosso mundo agora.

DIAS, L. P. M. The influence of the work of Wanda de Aguiar Horta to the brazilian nursing. Rev. Esc. Enf. USP, São Paulo, 22 (special issue): 14-20, June 1988.

The author makes comments on the life and the work of Dra. Wanda de Aguiar Horta, pointing out the most important aspects which influenced the development of nursing in Brazil. The paper had as guideline the work of Júnia Villela Gonçalves.

UNITERMS: Wanda de Aguiar Horta. Nursing - Brasil. 
- Wanda amiga:

Aqui, continuamos lutando

Por uma prática adequada

A sociedade brasileira

Por inteira;

Bem voltada para a saúde

Amiúde;

Preocupada com o coletivo;

Incisivo;

Empenhada com o autocuidado,

De aprendizado;

Com novo apoio legal

Menos mal;

- Lembras do Congresso em

[Fortaleza

Enquanto as dunas se alteavam

Para mim, alí

[nas praias?

Determinou-se intenção,

Vez e voz

[disposição

Crítica e ação

Alí muitos adotaram o desafio

Como as areias finas lá do

[Ceará...

Dalí a história vem...

Como convém.

- Os enfermeiros saíram da

[clausura

Não se entregaram a sua arte Comprometeram-se, participaram Mediram o cenário em que

Engajaram-se

Nos fatos do mundo

Tão fecundo!

Legitimaram um caminho:

Da decisão, do direito,

Da prerrogativa,

De alguém.

[viviam
- Os problemas da classe Pouco a pouco vêm sendo

Apurados.

[estudados

A profissão, fortemente feminina, Correlaciona seus problemas,

Seus dilemas,

Com os da mulher.

Como requer;

Assim também a Constituição

E alvo de muita atenção:

Participação!

Recebe de nós crítica e apoio

Separa o trigo do joio

Combate a alienação.

Por que não?

- Parece que encontramos agora Um caminho interessante

A enfermagem sai de si

Visualiza de per si

Todo seu determinante

Conhece o que the bloqueia

Assume o que the é próprio

Resgata o seu vivido

Tão sofrido e...

Desvenda o que lhe fraqueja.

Assim seja.

- As notícias que te damos

Podes ver são como as tuas

Desassombradas!

Tu sabias e as viveste

No início de tudo

Contudo

Agora podes sorrir

Estamos caminhando

Em movimento nunca visto

Audaz, ampliado e por tudo isto

Novos ventos sopram na ABEn.

Amém. 